\title{
Atypical tumors of the facial nerve: case series and review of the literature
}

\author{
Lindsey Ross, M.D., ${ }^{1}$ Doniel Drazin, M.D., ${ }^{1}$ Paula Eboli, M.D., ${ }^{1}$ \\ and Gregory P. Lekovic, M.D., Ph.D. ${ }^{1,2}$ \\ ${ }^{1}$ Department of Neurosurgery, Cedars-Sinai Medical Center; and ${ }^{2} H o u s e$ Clinic/House Research Institute, \\ Los Angeles, California
}

Object. The authors present a series of 4 patients with rare facial nerve tumors. The relevant literature is reviewed and is discussed regarding diagnostic features, the role of operative management, and surgical approach.

Methods. A retrospective chart review was conducted for patients with tumors of the facial nerve that were treated between 2008 and 2011. Patients undergoing observation with serial MRI and those who were treated with up-front radiosurgery and for whom tissue diagnosis was not available were excluded. In addition, patients with suspected vestibular schwannoma, facial nerve schwannoma, neurofibromatosis Type 2 , and metastatic disease were also excluded. The charts of 4 patients ( 2 men and 2 women) with "atypical" tumors were reviewed and analyzed.

Results. A total of 12 patients with tumors of the facial nerve were identified during the study period. Patient characteristics, preoperative imaging, operative approach, tumor histology, and outcomes are described.

Conclusions. Atypical facial nerve tumors must be distinguished from the more common facial nerve schwannoma. How the authors of this study treat rare facial nerve tumors is based on their experience with the more common facial nerve schwannomas, characterized by a slow progression of symptoms and growth. Less is known about the rare lesions, and thus a conservative approach may be warranted. Open questions include the role of radiosurgery, facial nerve decompression, and indications for resection of tumor and cable grafting for these rare lesions. (http://thejns.org/doi/abs/10.3171/2013.1.FOCUS12380)

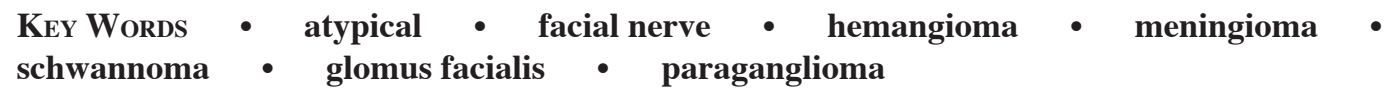

$\mathrm{P}$ RIMARY tumors of the facial nerve are uncommon lesions. Facial nerve schwannomas of the CPA and/or IAC are the most often encountered facial nerve tumors and may be mistaken for vestibular schwannomas. We present a series of 4 patients with "atypical" tumors of the facial nerve based on 1) location (not involving the CPA or IAC) and/or 2) unusual histological findings. Although individually very rare, these atypical tumors in aggregate contribute significantly to pathology of the facial nerve. The goal of the present study is to highlight the diversity of conditions affecting the facial nerve with a review of the relevant literature and discussion of nuances in diagnostic features. The role of operative management and surgical approach will also be discussed.

Abbreviations used in this paper: $\mathrm{CPA}=$ cerebellopontine angle; $\mathrm{IAC}=$ internal auditory canal.

\begin{abstract}
Methods
Retrospective Chart Review

The charts of all patients with tumors of the facial nerve treated between 2008 and 2011 by the senior author (G.P.L.) were retrospectively reviewed. Patients undergoing observation with serial MRI and those who were treated with upfront radiosurgery and for whom tissue diagnosis was not available were excluded. In addition, patients with suspected vestibular schwannoma, facial nerve schwannoma, neurofibromatosis Type 2, and metastatic disease were also excluded. Preoperative and postoperative imaging studies including CT scanning of the temporal bone and MRI were reviewed by an independent neuroradiologist. Facial nerve outcomes were evaluated based on House-Brackmann grade at presentation and at last follow-up (Table 1).
\end{abstract}


L. Ross et al.

TABLE 1: Patient characteristics and surgical diagnosis in the 4 patients illustrated in this paper

\begin{tabular}{cccc}
\hline Case No. & Preop House-Brackmann Grade & Time From Onset of Symptoms & Surgical Pathology \\
\hline 1 & III & $2 \mathrm{mos}$ & paraganglioma \\
2 & $\mathrm{VI}$ & $10 \mathrm{mos}$ & schwannoma \\
3 & $\mathrm{I}$ & $1 \mathrm{yr}$ & meningioma \\
4 & $\mathrm{I}-\mathrm{II}$ & $5 \mathrm{yrs}$ & hemangioma \\
\hline
\end{tabular}

\section{Literature Review}

A systematic search was performed using the PubMed and MEDLINE databases to identify case series involving facial nerve hemangiomas, facial nerve meningiomas, and facial nerve glomus tumors (Table 2). Initial key words included "facial nerve hemangioma" and "intratemporal hemangioma," which yielded 218 results. After systematic review, we were able to locate 9 complete articles with case reports in the English-language literature. When searching for case reports discussing facial nerve meningiomas, we used the key words "facial nerve meningioma." This yielded 33 results, of which 7 were complete articles. Finally, "facial nerve glomus tumor" and "paraganglioma facial nerve" were the key words used to locate case reports of glomus facialis tumors. There were 156 resulting articles, most of which described the more common glomus jugulare. Our search yielded a total of 9 case reports in the literature to date. We excluded all case reports that refrained from disclosing details related to presentation, diagnostics, and management, leaving 7 articles for review.

\section{Results}

A total of 12 patients with tumors of the facial nerve were identified during the study period. Preoperatively identified facial nerve schwannomas treated with up-front radiosurgery $(n=2)$ or with resection and cable grafting ( $=2$ ) were excluded from analysis. In addition, a facial nerve schwannoma diagnosed intraoperatively during surgery as a presumed vestibular schwannoma $(n=1)$ and a metastatic tumor to the CPA $(n=1)$ causing facial weakness were excluded from analysis. Finally, tumors that were believed to be facial nerve schwannomas based on imaging and that had been managed with a "wait and scan" approach were similarly excluded $(n=2)$. One tumor that was isolated to the mastoid segment of the facial nerve and that exhibited radiographic features believed to be unusual for schwannoma was found at surgery to be a schwannoma; this case was included because the tumor was not identified preoperatively as a facial nerve schwannoma (see Case 2 below). The charts of the 4 patients with "atypical" tumors of the facial nerve were reviewed and analyzed.

\section{Patient Characteristics}

There were 2 men and 2 women. The mean age was 53 years old. All 4 patients presented with some degree of facial paresis, except the patient in Case 3; the length of time from onset of facial weakness to diagnosis was 21 months. Three of the 4 patients had a history of remote Bell palsy, after which a complete recovery was made.
Surgical interventions included facial nerve decompression $(\mathrm{n}=3)$, partial tumor resection and/or biopsy ( $=3$ ), and tumor resection with interposition cable graft (n $=1$ ). The approach was via a middle fossa craniotomy (n $=2$ ) or a transpetrosal one $(n=2)$. Tumor histology was consistent with a hemangioma of the facial nerve $(n=1)$, meningioma $(n=1)$, schwannoma $(n=1)$, and a glomus facialis tumor $(n=1)$.

The mean preoperative House-Brackmann facial nerve grade was III. The mean House-Brackmann facial nerve grade at last follow-up was II. There was no major perioperative morbidity or death.

\section{Illustrative Cases}

\section{Case 1}

This 52-year-old woman presented with a 2-month history of right facial weakness. She developed Bell palsy on the right side more than 10 years previously, which had resolved within a few days with steroids and antiviral medication. This time, however, she did not respond to steroids. For this reason, MRI and CT scanning of the temporal bone were performed. These studies showed a right $10 \times 12-\mathrm{mm}$ skull base lesion situated within the right mastoid with some degree of contrast enhancement consistent with a neoplasm (Fig. 1). Differential considerations included glomus tumor and schwannoma. On examination, the patient was intact except for facial weakness (House-Brackmann Grade III). The patient underwent a right transtemporal craniotomy including mastoidectomy and decompression of the sigmoid sinus with microsurgical resection of the extradural skull base paraganglioma and decompression of the vertical segment of the facial nerve from the facial recess to the stylomastoid foramen. Surgical pathology was compatible with paraganglioma. The patient had worsening facial paresis postoperatively (House-Brackmann Grade VI) that at last follow-up (13 months) improved back to the preoperative level (House-Brackmann Grade III); there has been no progression of residual tumor.

\section{Case 2}

This 77-year-old man presented with left facial weakness that progressed over a period of 9 months. Magnetic resonance imaging with and without contrast showed a left temporal tumor, which involved the vertical segment of the facial nerve (Fig. 2). The CT scan showed an expansive lytic process involving the left facial nerve region. Differential diagnosis included neoplastic processes arising from the facial nerve or from the jugular fossa 


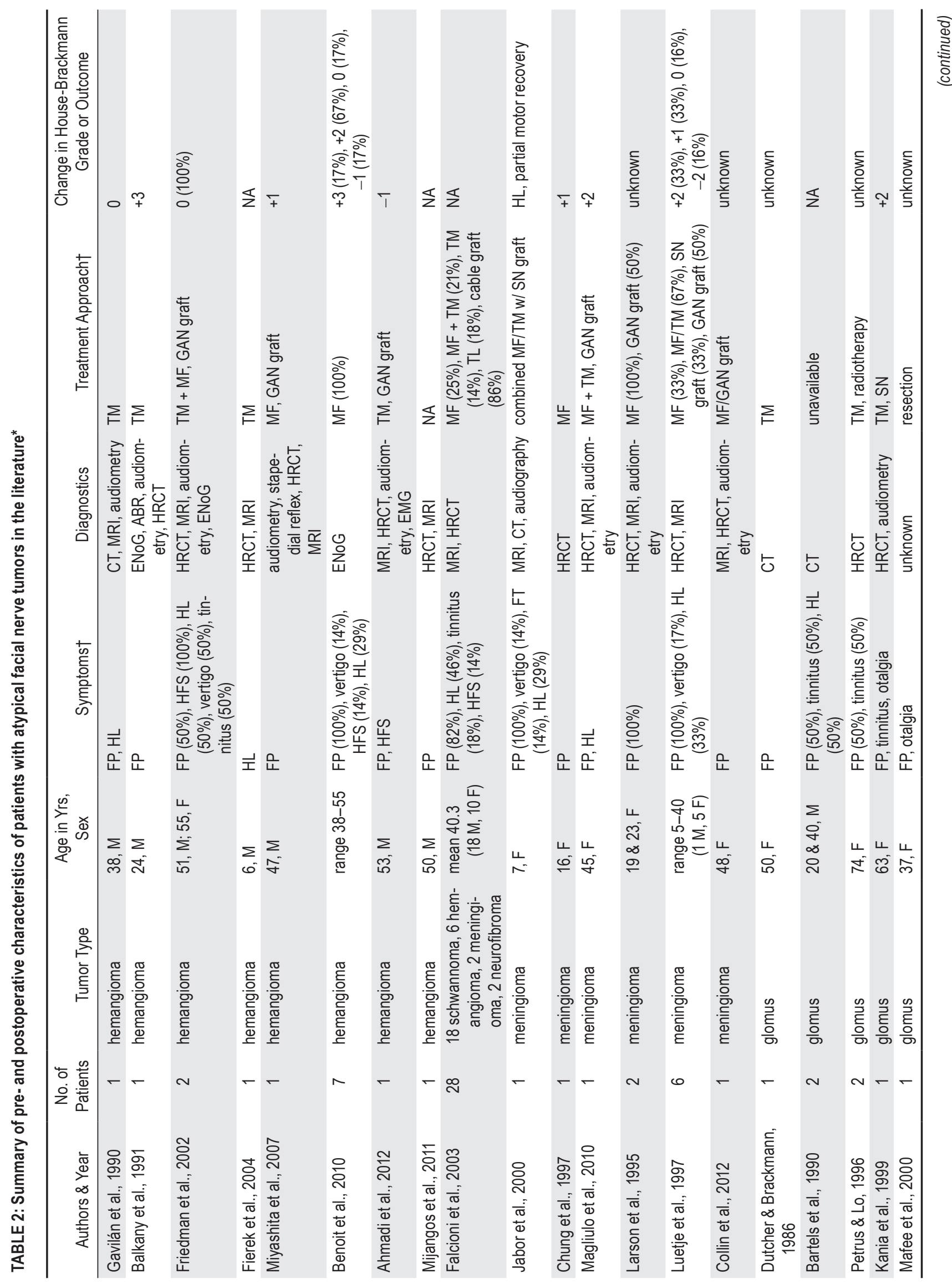




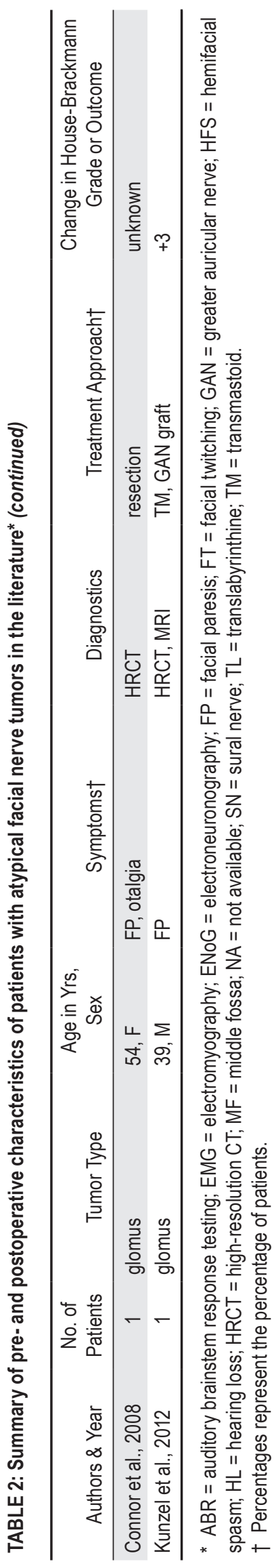

involving the facial nerve. On examination, he was intact except for severe facial weakness (House-Brackmann Grade VI). The patient underwent the following procedures: postauricular intratemporal craniotomy with microsurgical resection of the facial nerve schwannoma, interposition graft of the facial nerve with a collagen tubule and $15-\mathrm{cm}$ harvest of the sural nerve, parotidectomy, and tympanoplasty with ossicular reconstruction. The surgical specimen was compatible with a schwannoma (WHO Grade I). At last follow-up (12 months), the patient had no significant improvement in facial nerve function and was referred for a facial sling procedure.

Case 3

This 49-year-old man presented with right ear fullness lasting 1 year and 1 episode of dizziness 2 years prior (from which he had a full recovery). Magnetic resonance imaging and CT temporal bone studies showed a right enhancing temporal bone mass and enlargement of the facial nerve along the geniculate ganglion, most consistent with hemangioma followed by facial nerve schwannoma and meningioma (Fig. 3). On physical examination, the patient was intact. The patient underwent a combined transmastoid and middle fossa craniotomy with resection of extradural skull base tumor and tegmen reconstruction. Surgical pathology was compatible with meningioma (WHO Grade I). Although he continued to have some right ear pressure, the patient's otological examination revealed normal findings.

\section{Case 4}

This 37-year-old woman presented with a 5-year history of vertigo. Three years later she developed Bell palsy. Since then, she has complained of left facial weakness and synkinesis and received Botox injections in January 2010. Despite this treatment, she continued to have facial weakness. Findings from initial imaging, including MRI performed 5 years earlier, were thought to be negative. Subsequent imaging demonstrated slight irregular enhancement of the labyrinth and geniculate segment of the facial nerve. Her CT scanning examination showed an ossified lytic spiculated lesion in the area of the geniculate segment of the facial nerve (Fig. 4). On physical examination, the patient was intact except for mild left facial asymmetry and House-Brackmann Grade I-II left facial weakness. Differential diagnosis included an inflammatory process versus a benign neoplasm such as facial nerve schwannoma or hemangioma. The patient underwent a left middle fossa craniotomy for resection of the tumor and facial nerve decompression. Surgical pathology was compatible with hemangioma. Postoperatively, she did well and her face was symmetric (HouseBrackmann Grade I).

\section{Discussion}

We present a series of rare facial nerve tumors with features atypical from those seen in the more common facial nerve schwannoma, which in autopsy series may have an incidence as high as $0.8 \% .{ }^{36}$ Facial nerve schwan- 

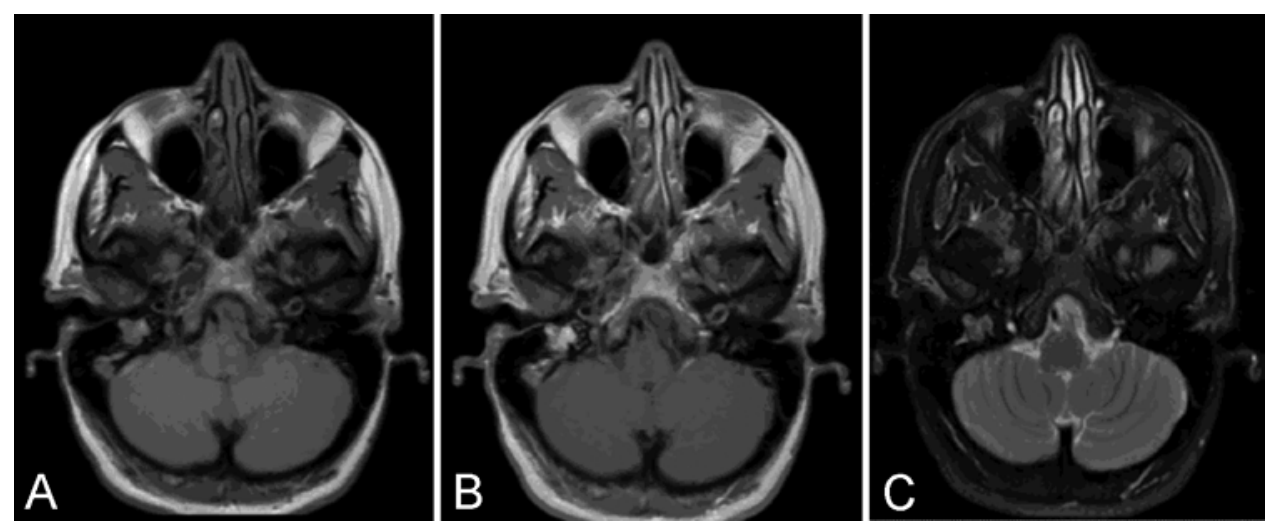

FIG. 1. Preoperative axial precontrast (A), postcontrast T1-weighted (B), and T2-weighted (C) MR images revealing a right 10 $\times 12-\mathrm{mm}$ skull base lesion situated within the right mastoid.

nomas typically involve the geniculate ganglion, IAC, and CPA (Fig. 5). Facial nerve schwannomas, such as the case included here, entirely confined to the temporal bone are exceedingly rare.

Facial nerve hemangiomas were first described by Politzer in 1901. ${ }^{25}$ Again, this lesion has a predilection for the geniculate ganglion. Once thought to occur here as result of pertinent anastomosis, it has recently been found to arise as a consequence of its dense capillary but anatomically distinct network. When compared with the neighboring segments of the geniculate ganlgion (that is, the tympanic and labyrinthine segments), there are upward of 46 cases reported in the literature of facial nerve hemangioma involving the geniculate ganglion. ${ }^{2}$ Hemangiomas are also commonly known as benign vascular tumors. There is evidence to prove that facial nerve hemangiomas should be correctly categorized as venous malformations, given the lack of internal elastic laminae noted on histological examination. ${ }^{1,4}$ In fact, Benoit et al. ${ }^{4}$ attempted to reclassify facial nerve hemangiomas using histological and immunohistochemical markers in the context of commonly accepted vascular lesion nomenclature. The distinction is understood when the true definition is studied. Benign vascular tumors arise directly from cellular hyperplasia, whereas malformations arise from errors in vascular morphogenesis. ${ }^{4}$

Facial nerve hemangiomas usually present in midlife, specifically between the 3rd and 6th decades. There appears to be an equal distribution of males and females. Approximately $97 \%$ of patients with atypical facial nerve tumors present with some degree of facial nerve deficit. ${ }^{14}$ Quite often, there is a spectrum of motor deficit that varies from hemifacial spasms to facial paresis. Hearing loss is also common and may be characterized as conductive if the horizontal segment of the facial nerve is involved or sensorineural if the tumor affects the labyrinthine segment or geniculate ganglion. Again, ipsilateral hearing loss is the most prevalent presenting symptom. Nonetheless, the deficit often is slow in progression or renders a recurrent episodic course, which allows us to make the distinction between other facial nerve tumors. Patients are often misdiagnosed and treated for idiopathic facial nerve weakness (Bell palsy), a much more common etiology of facial nerve paresis. The temporal characteristic of facial paralysis is of utmost importance in diagnoses. With Bell palsy, $85 \%$ of patients experience recovery of facial paresis to House-Brackmann Grade I or II in approximately 8-12 weeks, whereas patients with atypical facial nerve tumors, such as facial nerve hemangiomas, often experience a more indolent course without recovery of facial motor function. Uniquely, facial nerve hemangioma size is not directly correlated to the extent of deficit. Small tumors $(<10 \mathrm{~mm})$ may lend themselves to grave deficits. There is debate in the literature with respect to the etiology of the neurological deficit. Previous reports in the literature have claimed that facial nerve deficits arise as a consequence of direct compressive forces; newer schools of thought believe that there is an element of a vascular steal phenomenon wherein blood flow to the highly vascular facial nerve is detoured toward the tu-
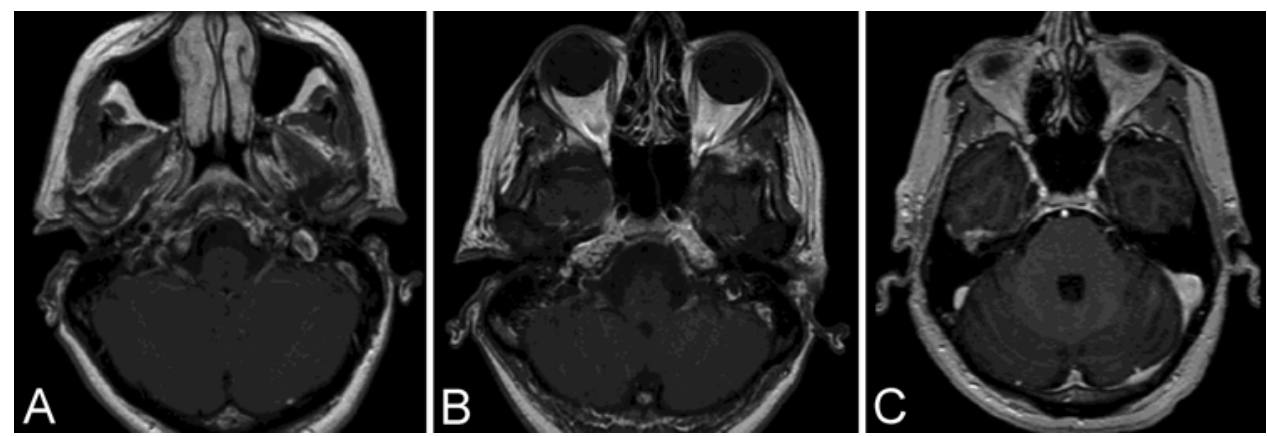

FIG. 2. Preoperative axial precontrast (A) and postcontrast T1-weighted (B and C) MR images revealing a left temporal tumor, which involves the vertical segment of the facial nerve. 


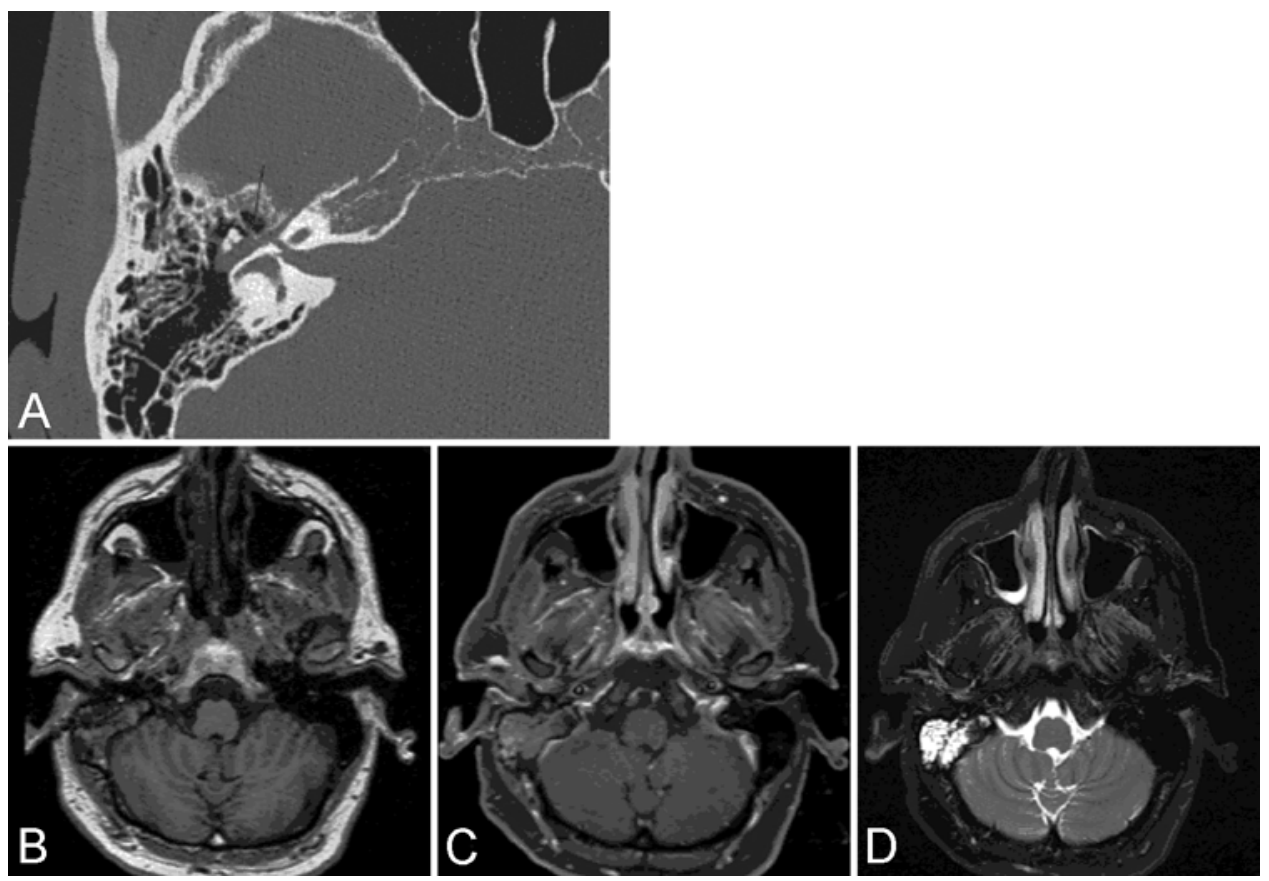

Fig. 3. Preoperative temporal bone CT scan (A) and axial precontrast (B), postcontrast T1-weighted (C), and T2-weighted (D) MR images demonstrating a right enhancing temporal bone mass and enlargement of the facial nerve along the geniculate ganglion.

mor, resulting in ischemic insult. ${ }^{4,35}$ For this reason, facial nerve schwannomas of similar size may lead to less severe cranial nerve dysfunction. ${ }^{26}$

The relationship between facial nerve hemangioma and cavernous malformations isolated to the seventh cranial nerve is controversial. Deshmukh et al. ${ }^{8}$ described 2 patients who presented with acute hearing loss and facial nerve paresis; MRI revealed hyperintense lesions, without contrast enhancement, which were found to have small cavernous malformations. Importantly, extraaxial cavernous malformations may also enhance following the administration of $\mathrm{Gd}$, so the presence of enhancement is not sufficient to rule out the presence of a cavernous malformation. The incidence of these lesions is too low to determine whether these lesions are truly distinct from facial nerve hemangioma, or merely histological variations of the same clinicopathological entity.
Although meningiomas are the second most common tumor of the CPA, geniculate meningiomas are exceedingly rare. ${ }^{27}$ Although the etiology is unclear, noted associations with progesterone, breast cancer, and radiation therapy have been described. ${ }^{17}$ Meningiomas arise from arachnoid villi, which are invaginations of the arachnoid mater along the walls of the dural and venous sinuses. They are also located along the neural foramina of the cranial nerves. Facial nerve meningiomas most likely arise from the arachnoid villi along the porus acousticus (opening between the CPA cistern and IAC) and gasserian envelope. This can be explained embryonically. The seventh and eighth cranial nerves arise from a common primordium. At 5 weeks of gestation, the fibers of the facial nerve exit the neural tube along with a sheath of arachnoid and dura. Although the dura terminates at the IAC, the arachnoid may continue toward the geniculate
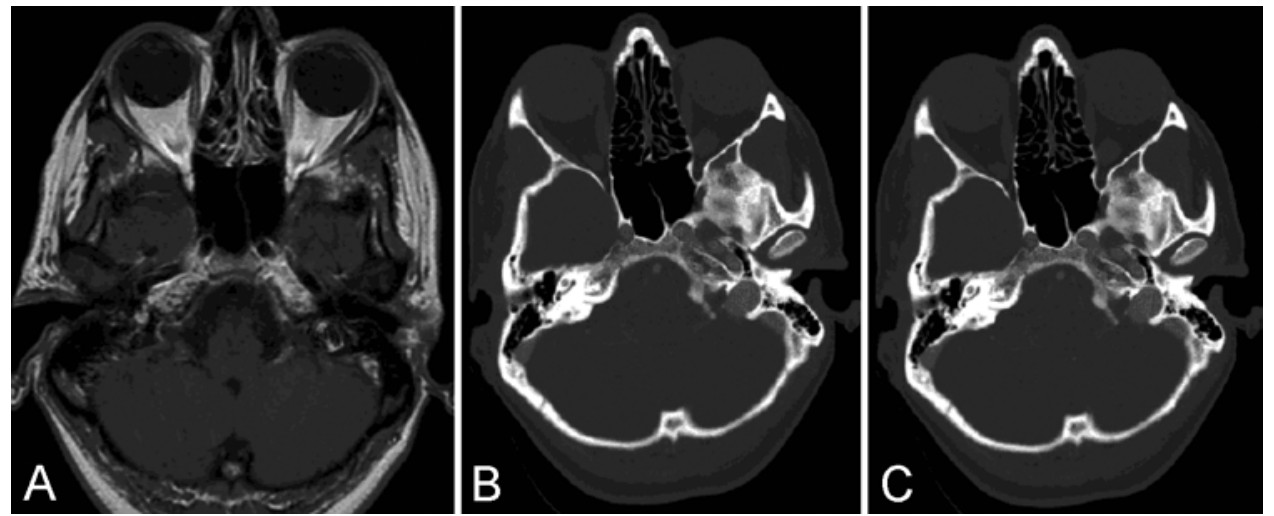

FIG. 4. Preoperative axial postcontrast T1-weighted MR image (A) and axial CT images (B and $C$ ) showing a spiculated lesion in the area of the geniculate segment of the facial nerve. 


\section{Atypical tumors of the facial nerve}

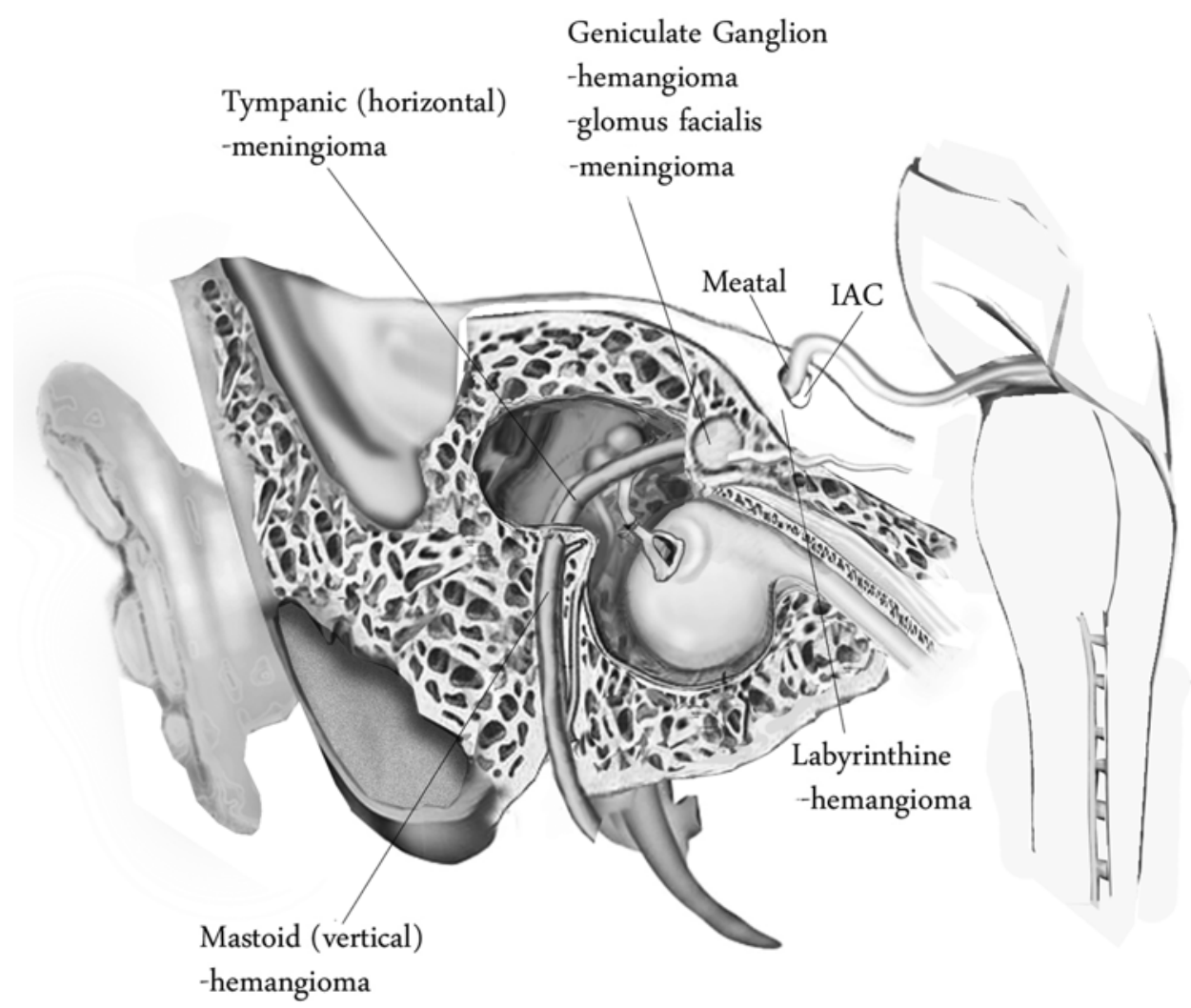

FIG. 5. Atypical facial nerve tumor illustration. Diagram by Lindsey Ross and Brian Nicholas. Printed with permission from Lindsey Ross, M.D.

ganglion and beyond as it gradually fuses with endoneurium. ${ }^{19,31}$ Extracranial extension of a neural foramen meningioma is quite rare. More commonly, the tumor would originate intracranially and extend extracranially.

Glomus tumors are also known as paragangliomas or chemodectomas that arise from chemoreceptor cell derivatives of neural crest cells. They originate from paraganglionic tissue typically at the carotid bifurcation (carotid body tumors), jugular foramen (glomus jugulare), vagus nerve (glomus vagale), and tympanic plexus (glomus tympanicum) ${ }^{21}$ They may occur sporadically or as a part of hereditary syndromes such as multiple endocrine neoplasia Type II (MEN II), von Hippel-Lindau syndrome, and neurofibromatosis Type $1 .{ }^{21}$ In $80 \%$ of hereditary cases and $20 \%$ of sporadic cases, the patient presents with multiple lesions.

A landmark histological study by Guild in 1941 described 73 temporal bone paragangliomas..$^{32}$ The thought is that the glomus tumor may arise from the Arnold nerve, an auricular branch of the vagus nerve that traverses through the mastoid canaliculi from the jugular bulb, superior to the fallopian canal at the stylomastoid foramen, where an ascending branch merges with the facial nerve. This is the same nerve that gives rise to glomus jugulare and glomus tympanicum. ${ }^{9}$

\section{Preoperative Evaluation}

Any patient with a suspected tumor of the facial nerve should be evaluated with high-resolution CT scanning of the temporal bone, MRI with and without contrast, and direct otoscopic examination. Large tumors involving the tympanic segment of the facial nerve may be visible on otoscopic examination. Gross features such as vascularity may aid in diagnosis, and transcanal biopsy may be performed in select cases. Electroneurography may also be of assistance in select cases.

Careful review of preoperative radiographs may help to establish the diagnosis of facial nerve schwannoma, especially in the presence of geniculate ganglion enhancement, anterior position of the tumor in the IAC, or linear enhancement of the facial nerve in the mastoid temporal bone. ${ }^{38}$ Schwannomas will typically create a smooth but enlarged course along the fallopian canal and may be differentiated from hemangiomas, which lack distinct margins and often contain bony spicules on thin-cut CT. They will also enhance on postcontrast T1-weighted MRI.

Facial nerve hemangiomas are best visualized via high-resolution CT scanning of the temporal bone, namely enlargement of the fallopian canal with a lesion exhibiting irregular margins, amorphous shape, and possibly intratumoral bony spicules. The typical honeycomb or sunburst radiographic appearance is indicative of an ossifying hemangioma. This occurs as a result of osteoclastic remodeling resulting in intralesional lamellar bony trabeculae. ${ }^{4,29}$ The honeycomb sign is pathognomonic for hemangioma and helps to differentiate between schwannoma and meningioma. Nevertheless, this is present only $50 \%$ of the time. ${ }^{11}$ This is also known as an ossifying hemangioma. ${ }^{29}$ Magnetic resonance imaging of the brain, 


\section{Ross et al.}

with thin-cut sequences through the temporal bone at the IAC, is used if the lesion is not visualized. One would expect to see iso-, hyper-, or variable intensity on T1weighted images and hyperintensity on T2-weighted images as well as enhancement with $\mathrm{Gd}$ contrast. Of note, one would expect normal variations of mild to moderate enhancement of certain aforementioned highly vascularized segments of the facial nerve, namely the geniculate ganglion and tympanic and labyrinthine segments.

Circumferential expansion of the facial nerve canal with well-preserved margins and smooth architecture are typical findings in cases of glomus facialis and are findings comparable to characteristics of schwannoma on CT scanning. Magnetic resonance imaging of the temporal bone, when performed, may reveal a pathognomonic salt-and-pepper pattern as described by Olsen et al. ${ }^{33}$ in paragangliomas larger than $2 \mathrm{~cm}$. Otherwise, the lesion has been noted to show hypointensity to muscle on T1weighted imaging and heterogeneous enhancement with Gd contrast injection. On T2-weighted imaging, there is isointensity to muscle. ${ }^{18}$ Angiographic findings include hypervascularity, an enlarged feeding artery, and possible draining vein. This often assists in diagnosis, as rapid arteriovenous shunting is not seen in hemangiomas.

\section{Management}

Due to their rarity, there is little guidance in the literature for the appropriate management of facial nerve tumors. Recommendations may be reasonably extrapolated from the approach to the more common facial nerve schwannoma. Many authors, including Shirazi et al., ${ }^{37}$ have advocated conservative treatment of facial neuromas when patients present without facial motor and hearing deficits. $^{20,28}$ Treatment strategies include radiological observation, drainage of any cystic component of the tumor for histological diagnosis, and/or bony decompression of the tumor. ${ }^{37}$ Even decompression may lend itself to a delayed management approach in attempts at preserving residual nerve function. Nevertheless, if the lesion is symptomatic, resection with attempts at anatomical continuity is the gold standard. Surgical approaches include the most commonly used translabyrinthine approach, as well as the retrosigmoid approach, transmastoid or middle fossa approach, combined middle fossa-transmastoid approach, and transmastoid-transparotid approach. This is often performed with a cable nerve graft interposition of either the sural or greater auricular nerve. Falcioni et al. ${ }^{12}$ stated that the chances of satisfactory facial nerve recovery decreases significantly postoperatively if resection is not performed within the 1st year of initial clinical facial nerve dysfunction.

Hemangiomas of the facial nerve at the geniculate ganglion are best approached through the middle fossa. If the vertical segment of the facial nerve is involved and hearing is preserved, a transmastoid approach appears to obtain the best visualization. Often a combined approach is appropriate. Upon dissection a soft, dark red, or even blue, easily dissectible mass will be encountered. As a consequence, the facial nerve is often salvageable. Surgery should be offered within the 1st year of diagnosis, prior to perineural fibrosis, or actual neural infiltration develops, making resection more difficult. ${ }^{1}$ Facial nerve decompression and removal of any compressive bony spicules may prolong facial function and minimize the chances of postoperative worsening of facial paresis. Aggressive resection will likely exacerbate preexisting facial paresis and is warranted only in cases of high-grade facial nerve dysfunction (House-Brackmann Grade V or VI).

If resection is appropriate, cable grafting such as with a greater auricular nerve graft may be used. This intervention may preserve facial nerve function in the range of $50 \%-75 \% .10$

\section{Role of Radiosurgery}

Recently, our group has published on the changing paradigm for treatment of facial nerve schwannoma, with an increased reliance on radiosurgery for the treatment of these tumors. ${ }^{39}$ This is often performed on the basis of MRI and CT imaging alone (that is, without tissue diagnosis). While radiosurgery has had generally favorable results for the treatment of facial nerve schwannoma, the role of radiosurgery in these atypical tumors, especially facial nerve hemangiomas, is less clear.

Other rare causes of facial nerve paresis from tumor involvement of the intratemporal facial nerve include epidermoid (cholesteatoma), metastasis, and direct invasion from skull base carcinoma. The facial nerve perineurium serves as a gateway to the temporal bone for neoplasms such as parotid mucoepidermoid carcinoma, benign pleomorphic adenoma of the parotid gland, and squamous cell carcinoma. ${ }^{16}$ Tumors extrinsic to the intratemporal segment including primary temporal bone tumors, pontine gliomas, and parotid tumors may also affect facial nerve function.

\section{Conclusions}

Much of how we approach facial nerve tumors arises from experience with the natural history of facial nerve schwannomas, characterized by indolent symptomatic progression and slow growth. However, less is known about the natural history of these atypical lesions. In the absence of sufficient clinical data to prove otherwise, a conservative approach may be warranted. Open questions include the role of radiosurgery, facial nerve decompression, and indications for resection of tumor and cable grafting for these rare lesions.

\section{Disclosure}

The authors report no conflict of interest concerning the materials or methods used in this study or the findings specified in this paper.

Author contributions to the study and manuscript preparation include the following. Conception and design: Lekovic, Drazin. Acquisition of data: Ross, Eboli. Analysis and interpretation of data: Drazin, Ross, Eboli. Drafting the article: Drazin, Ross, Eboli. Critically revising the article: Lekovic, Drazin, Ross. Reviewed submitted version of manuscript: Lekovic, Drazin, Ross. Approved the final version of the manuscript on behalf of all authors: Drazin. Study supervision: Lekovic.

\section{References}

1. Ahmadi N, Newkirk K, Kim HJ: Facial nerve hemangioma: a 
rare case involving the vertical segment. Laryngoscope [epub ahead of print], 2012

2. Balkany T, Fradis M, Jafek BW, Rucker NC: Hemangioma of the facial nerve: role of the geniculate capillary plexus. Skull Base Surg 1:59-63, 1991

3. Bartels LJ, Pennington J, Kamerer DB, Browarsky I: Primary fallopian canal glomus tumors. Otolaryngol Head Neck Surg 102:101-105, 1990

4. Benoit MM, North PE, McKenna MJ, Mihm MC, Johnson MM, Cunningham MJ: Facial nerve hemangiomas: vascular tumors or malformations? Otolaryngol Head Neck Surg 142:108114,2010

5. Chung CJ, Mukherji S, Fordham L, Boydston W, Hudgins R: Geniculate ganglion meningioma. Pediatr Radiol 27:847849,1997

6. Collin M, Bernardeschi D, Cazals-Hatem D, Sterkers O: Meningioma of geniculate ganglion: case report and review of the literature. Acta Otalaryngol [epub ahead of print], 2012

7. Connor SE, Gleeson MJ, Odell E: Extracranial glomus faciale tumour. J Laryngol Otol 122:986-989, 2008

8. Deshmukh VR, Albuquerque FC, Zabramski JM, Spetzler RF: Surgical management of cavernous malformations involving the cranial nerves. Neurosurgery 53:352-357, 2003

9. Dutcher PO Jr, Brackmann DE: Glomus tumor of the facial canal. A case report. Arch Otolaryngol Head Neck Surg 112: 986-987, 1986

10. Eby TL, Fisch U, Makek MS: Facial nerve management in temporal bone hemangiomas. Am J Otol 13:223-232, 1992

11. Escada P, Capucho C, Silva JM, Ruah CB, Vital JP, Penha RS: Cavernous haemangioma of the facial nerve. J Laryngol Otol 111:858-861, 1997

12. Falcioni M, Russo A, Taibah A, Sanna M: Facial nerve tumors. Otol Neurotol 24:942-947, 2003

13. Fierek O, Laskawi R, Kunze E: Large intraosseous hemangioma of the temporal bone in a child. Ann Otol Rhinol Laryngol 113:394-398, 2004

14. Friedman O, Neff BA, Willcox TO, Kenyon LC, Sataloff RT: Temporal bone hemangiomas involving the facial nerve. Otol Neurotol 23:760-766, 2002

15. Gavilán J, Nistal M, Gavilán C, Calvo M: Ossifying hemangioma of the temporal bone. Arch Otolaryngol Head Neck Surg 116:965-967, 1990

16. Gross BC, Carlson ML, Moore EJ, Driscoll CL, Olsen KD: The intraparotid facial nerve schwannoma: a diagnostic and management conundrum. Am J Otolaryngol 33:497-504, 2012

17. Jabor MA, Amedee RG, Gianoli GJ: Primary meningioma of the fallopian canal. South Med J 93:717-720, 2000

18. Kania RE, Bouccara D, Colombani JM, Molas G, Sterkers O: Primary facial canal paraganglioma. Am J Otolaryngol 20:318-322, 1999

19. Kettel K: Peripheral facial palsies due to tumors; pathology and clinical picture: a review of the literature and a report of three cases of intratemporal tumors of the facial nerve. AMA Arch Otolaryngol 69:276-292, 1959

20. Kim CS, Chang SO, Oh SH, Ahn SH, Hwang CH, Lee HJ: Management of intratemporal facial nerve schwannoma. Otol Neurotol 24:312-316, 2003

21. Kunzel J, Zenk J, Koch M, Hornung J, Iro H: Paraganglioma of the facial nerve, a rare differential diagnosis for facial nerve paralysis: case report and review of the literature. Eur Arch Otorhinolaryngol 269:693-698, 2012
22. Larson TL, Talbot JM, Wong ML: Geniculate ganglion meningiomas: CT and MR appearances. AJNR Am J Neuroradiol 16:1144-1146, 1995

23. Luetje CM, Syms CA III, Luxford WE, Storper IS, Glasscock ME III, Brackmann DE, et al: Meningiomas intrinsic to the geniculate ganglion. Am J Otol 18:393-397, 1997

24. Mafee MF, Raofi B, Kimar A, Muscato C: Glomus faciale, glomus jugulare, glomus tympanicum, glomus vagale carotid body tumors, and stimulating lesions. Role of MR imaging. Radiol North Am 38:1059-1076, 2000

25. Magliulo G, Alla FR, Colicchio G, Trasimeni G: Geniculate ganglion meningioma. Skull Base 20:185-188, 2010

26. Mangham CA, Carberry JN, Brackmann DE: Management of intratemporal vascular tumors. Laryngoscope 91:867-876, 1981

27. Maniglia AJ: Intra and extracranial meningiomas involving the temporal bone. Laryngoscope 88 (9 Pt 2 Suppl 12):1-58, 1978

28. McMonagle B, Al-Sanosi A, Croxson G, Fagan P: Facial schwannoma: results of a large case series and review. J Laryngol Otol 122:1139-1150, 2008

29. Mijangos SV, Meltzer DE: Case 171: facial nerve hemangioma. Radiology 260:296-301, 2011

30. Miyashita T, Hoshikawa H, Kagawa M, Mori N: A case report of facial nerve hemangioma. Auris Nasus Larynx 34:519522,2007

31. Nager GT: Meningioma involving the temporal bone: clinical and pathological aspects. Ir J Med Sci 41:69-96, 1966

32. O'Leary M, Shelton C, Giddings N, Kwartler J, Brackmann DE: Glomus tympanicum tumors: a clinical perspective. Laryngoscope 101:1038-1043, 1991

33. Olsen WL, Dillon WP, Kelly WM, Norman D, Brant-Zawadzki M, Newton TH: MR imaging of paragangliomas. AJR Am J Roentgenol 148:201-204, 1987

34. Petrus LV, Lo WM: Primary paraganglioma of the facial nerve canal. AJNR Am J Neuroradiol 17:171-174, 1996

35. Semaan MT, Slattery WH, Brackmann DE: Geniculate ganglion hemangiomas: clinical results and long-term follow-up. Otol Neurotol 31:665-670, 2010

36. Sherman JD, Dagnew E, Pensak ML, van Loveren HR, Tew JM Jr: Facial nerve neuromas: report of 10 cases and review of the literature. Neurosurgery 50:450-456, 2002

37. Shirazi MA, Leonetti JP, Marzo SJ, Anderson DE: Surgical management of facial neuromas: lessons learned. Otol Neurotol 28:958-963, 2007

38. Wiggins RH III, Harnsberger HR, Salzman KL, Shelton C, Kertesz TR, Glastonbury CM: The many faces of facial nerve schwannoma. AJNR Am J Neuroradiol 27:694-699, 2006

39. Wilkinson EP, Hoa M, Slattery WH III, Fayad JN, Friedman RA, Schwartz MS, et al: Evolution in the management of facial nerve schwannoma. Laryngoscope 121:2065-2074, 2011

Manuscript submitted November 16, 2012.

Accepted January 16, 2013.

Please include this information when citing this paper: DOI: 10.3171/2013.1.FOCUS12380.

Address correspondence to: Gregory P. Lekovic, M.D., Ph.D., House Research Institute, House Clinic Neurosurgical Associates, 2100 West Third Street, Los Angeles, California 90057. email: glekovic@hei.org. 